\title{
This special issue is dedicated to Professor Ron Steer
}

\author{
Special Editors: \\ William J. Leigh \\ McMaster University \\ Hamilton, Ontario \\ Matthew Paige \\ University of Saskatchewan \\ Saskatoon, Saskatchewan \\ David Palmer \\ University of Saskatchewan \\ Saskatoon, Saskatchewan
}

